\title{
The Use of Dialogue Journals in an ESL Writing Class from Vygotskyan Perspective
}

\author{
- Lal Bahadur Rana
}

\begin{abstract}
Dialogue journal writing is a way of communicating with the learners through constant written communication over a specified period. Since the teachers who use the dialogue journals do not require their students to be grammatically accurate in their expressions while they are writing journals, the students build their self-confidence. Consequently, they can increase their writing fluency, which ultimately leads to not only the development of writing but also overall language proficiency of the language they are learning. More importantly, it develops learners' theoretical thinking as they are involved in dialogic discussions through written interactive communications. It is because as per Vygotskyan theory of human development human beings are constantly engaged in interpersonal as well as intrapersonal communications, which expand learners'zones of proximal development.
\end{abstract}

Key words: Dialogue journal, Vygotskyan perspective, EFL/ESL Classroom, Zone of Proximal Development (ZPD), and Socio-cultural theory

\section{Introduction}

Dialogue journals, as their names imply, refer to the written dialogues or conversations that routinely take place between learners and their teacher and sometimes among learners themselves as well. These are "written conversations in which a learner and teacher (or another writing partner) communicate regularly (daily, weekly, or on a schedule that fits the educational setting) over a semester, school year or course" (Peyton, 2000, p. 3). Since the main purpose behind the use of dialogue journals in ESL or EFL classrooms is to enable learners to write for communication; rather than to improve grammar and learn vocabulary, they "write about thoughts, experiences, reactions to texts, or issues of importance to them, and teachers respond to the content of students' entries by sharing experiences, ideas, and reactions as well as modeling correct usage" (Auerbach, 1999). The topics on which learners 


\section{The Use of Dialogue Journals in an ESL Writing Class from Vygotskyan Perspective}

write their journal entries depend upon the negotiations between learners and their teacher based on the purpose, interest, and curriculum. Therefore, they can decide to write on a wide variety of topics, ranging from personal experience to reading responses.

\section{Characteristics of Dialogue Journals}

In order for journals to be recognized as dialogue journals, Peyton and Reed, (1990) maintain that they should have four major qualities. First, there should be the qualities of good conversations between the writers and readers even if they are in written forms. "Instead of evaluating or grading students' entries the teachers who use dialogue journals in their classrooms simply provide feedback to each entry in the form of a written response. In turn, students reply to the teacher after reading the teacher's response" (Davis, 1983 as cited in Tanner 1997). Thus, the interactive written conversations can cyclically continue until both the reader and writers have their queries about a particular journal entry are over. Second, they should be generated by the students on their own. In fact, learners write such journals to express themselves, to make sense of their own and others' experiences, and to develop their writing abilities. Third, they should have certain purposes behind writing journals. As mentioned earlier, they are for sharing writers' thoughts, feelings, lived experiences, etc. Fourth, writers should continually write them as prior-determined discussing with their teachers (readers). Given the inherent nature of these journals, while writing "learners write freely, without focusing primarily on form and correctness" (Peyton, 2000, p. 4).

\section{Benefits of Using Dialogue Journals in ESL or EFL Classrooms}

There are several benefits of using dialogue journals in ESL or EFL classrooms. According to Linnell (2010), there are three main benefits of using dialogue journals. To begin with, they are effective tools for dealing with the challenges of large classrooms. For instance, if there are fifty students in a class, teachers can hardly talk to each individual student of their class, but they can know about their students if they ask them to write journal regularly. Another advantage is that adult learners can bring their life experiences, social and cultural backgrounds in their classrooms that might inform other students about their classmates' lived experiences and socio-cultural backgrounds if they share to the whole class. As a matter of fact, it not only includes authentic information but also focuses on meaningful communications. Finally, dialogue journals can be good means for the acculturation, assimilation, and adjustment of ESL students.

Similarly, Denne-Bolton (2013) reviews the available literature related to the dialogue journals and discusses the following four advantages. First, writing fluency is increased when students keep on writing dialogue journals because they do not need to worry about the content and correctness. While writing such journals, they aim to express their-self, disregarding whether 
or not their sentences will be grammatically accurate so that they do not have pressure on maintaining grammatical accuracy and the structure of a certain genre, but the flow of their ideas. When they write focusing on their meanings or expressions over a relatively extended period, their writing fluency is significantly improved. Second, with the help of dialogue journals, students and teachers can build a good rapport between them. When they interact through written dialogues, they get to know each other. Reading their journal entries, the teachers know their students from various dimensions such as academic, social, personal, etc. Therefore, they can better cater the needs of the students by tailoring the tasks or texts that are suitable for them. "Through dialogue journals, teachers can become better acquainted with their students, in terms of both their learning progress and their affective states, and thus become better equipped to meet students' individual needs" (Brown \&Abeywickrama, 2010, pp. 134-135). Similarly, Miller (2007) says that dialogues journals are a means for teachers to better serve their learners' needs. When there exist mutual trust and good relationship between students and teachers, students can progress in their academic and social lives. Third, learners are empowered through dialogue journals. They bring their experiences which can be connected to the additional information or ideas they receive in the class for creating new knowledge. For this reason, they build a sense of ownership for the knowledge or meaning they create on their own. Finally, with the help of dialogue journals, second or foreign language learners' habit of editing the language before producing certain utterances or sentences can be avoided. Drawing from Krashen's monitor model hypothesis, Denne-Bolton (2013) calls this process writer's block, which she thinks can be dislodged with the help of dialogue journals as learners focus on their fluence or flow of their thoughts.

\section{Challenges of Using Dialogue Journals}

The teachers who like to use dialogue journals in ESL classrooms might face certain challenges in course of their implementation. Peyton (2000) discusses three things to be taken into their considerations while they are using dialogue journals in their classroom. To begin with, she says that some learners might like their errors to be corrected explicitly like in current traditional approach to teaching writing, irrespective of the fact that they are not expected to write perfectly, but meaningfully. Another main challenge is that related to the time that teachers and students invest for the successful use of dialogue journals because it requires students to write journal entries that are read by their teachers and some feedbacks are given to them. Based on the feedback, they might write responses. In this way, there can be cycles of writing and responses. Therefore, "many teachers find it difficult to find time to read and respond to learner entries" (Peyton, 2000, p. 5). Finally, writing can be overly personal. Some of the learners might write very personally, which is why there can be the issues of privacy, confidentiality, and self-disclosure. Likewise, Garmon (2001) points out that the use of dialogue journals can have some issues with journal requirements and procedures 


\section{The Use of Dialogue Journals in an ESL Writing Class from Vygotskyan Perspective}

because it is leaners might be writing in numerous ways. Similarly, another challenge is that of connecting the ideas of dialogue journal writing to the academic writing. Mostly, ESL writers study English for the sake of familiarizing themselves with the kinds of genres that they are likely to encounter in the content courses, for example, nursing, engineering and business studies. But the tasks or activities in the journal writing do not seem to have been clearly interlinked to academic writing.

\section{Theoretical Underpinnings of Dialogue Journals}

Dialogue journals are useful tools for enhancing both linguistic and higher mental functions. As such, those who use dialogue journals in their classrooms receive their impetuses from socio-cultural theories, especially from Vygotskyan theory of human development, which, in turn, has been influenced by Marxism. Regarding this influence, Wertsch (1985) has suggested that

Vygotsky's developmental approach was inspired by three principles of Marxist theory: 1) the notion that human consciousness is fundamentally social in origin; 2) that human activity is mediated by material artifacts (e.g., computers, physical tools) and psychological and symbolic signs (e.g., language, literacy, numeracy, concepts); and 3) that units of analysis for understanding human activity and development should be situated and holistic in nature (as quoted in Thorne and Hellermann, 2015, p. 282).

His own prodigious contributions to the theory and method coupled with these influences enabled him to propose the dialectical relationships between social and individual, biology and culture. As per him, these factors are in mutually influential, and they also determine the social as well as individual development of a person. From this perspective, it can be said that society (material) can change individuals and vice versa. In the similar vein, culture and biology are also in constantly dialogic conditions.

Dialogue journals also seem to have been related to various theories or hypotheses of second language acquisition, for instance, monitor model hypothesis and affective filter hypothesis (Krashen,1982), interaction hypothesis (Long, 1996) and output hypothesis (Swain, 1995). As per the monitor model hypothesis, the learners can give better output if they are not involved in editing their languages before they produce. Similarly, affective filter hypothesis maintains that the affects such as facilitating anxiety, motivation, self-confidence, etc. should be high so that learners can unblock mental blocks and thereby accelerate the speed of their language acquisition. As per the basic tenet of interaction hypothesis, receiving input is not sufficient in order for learners to be able to speak. Therefore, the input should be accompanied by some sorts of interactions between the native speakers or the people who have higher proficiency than those of learners. Regarding this, Long (1996) maintains that "negotiation for meaning 
and especially negotiation work that triggers interaction adjustments by the NS [native speakers] or more competent interlocutor, facilitates acquisition because it connects input, internal learner capacities, particularly selective attention, and output in productive ways" (p. 451-452). Likewise, output hypothesis as proposed by Swain (1985) proposes that through producing language, either spoken or written, language and acquisition may occur.

Although most of these theories are related to the spoken forms of language, they are related to written forms as well in a sense that the written form of a particular language is a manifestation of the spoken form. Vygotsky's theory considers language primarily a culturally created symbolic tool like mathematics, which mediates human's social or material plane with the psychological or mental plane. Thus, for Vygotsky, the development of language is, therefore, very crucial for one's mental as well as social development. With the help of the language, human beings engage themselves in communications interpersonally and intrapersonally. This notion can have very high significance in dialogue journal writing because they are involved in dialogic interactions with their teachers by means of written language. They can also be constant interactions with themselves while they are in any stage of writings such as planning, drafting, and editing. Similarly, writing dialogue journals can draw from the theory of second language learning. From the monitor model hypothesis, the learners who are involved in writing might not care about their accuracy, but the meanings or messages that like to communicate. When they do not have the sense of being fooled or punished for making mistakes, they might focus on their writing fluency. The other two hypotheses can also be very important in a sense that the more the learners interact the better output they can give.

\section{Dialogue Journals and Some Theoretical Constructs of Vygotskyan Socio-cultural Theory}

There are some key theoretical constructs of the Vygotskyan socio-cultural theory of human development such as the zone of proximal development and internalization. In what follows include the discussions on how dialogue journals are related to these constructs.

\section{Dialogue Journal and Zone of Proximal Development}

Zone of proximal development is one of the main constructs in the socio-cultural theory of human development, which refers to "the distance between the actual developmental level as determined by independent problem solving and the level of potential development as determined through independent problem solving under adult guidance or in collaboration with more capable peers" (Vygotsky, 1978, p. 86). It "represents, in particular, a concrete and programmatic manifestation of Vygotsky's broader theoretical contention regarding the genetic relationship between interpsychological and intrapsychological functioning" (Cheyne \&Tarulli, 1999, p. 15). Originally, Vygotsky proposed the concept of ZPD while he as critiquing the traditional approach of intelligence testsor some kinds of standardized tests which would 


\section{The Use of Dialogue Journals in an ESL Writing Class from Vygotskyan Perspective}

mainly focus on the end-product; rather than assessing what learners can potentially do.

As per the fundamental features of this construct, a teacher should involve learners in those tasks or activities that they cannot do, but can do with some kind of assistance from teachers or peers who have already mastered the skills to carry out those tasks or activities. The implication is that learners can better learn if they get assistance within their ZPDs. However, the issue is of how to give the differentiated tasks or activities in a single classroom, because all learners may not necessarily be at the same ZPD. Undoubtedly, it might be hard for a teacher to manage his or her assistance as per all students' ZPDs. Nevertheless, it is not impossible. One of the strategies can be the use of dialogue journals in writing classrooms so that each student can be approached and assisted within his or her ZPD by their teacher. Here, the written interactions between a student and his or her teacher serve as a tool to mediate between student's ZPD and the assistance offered by the teacher in the form of written questions or comments. The ZPD of a student, on the other hand, links "the social discourse of teachers and learners with the cognitive dimensions of students' learning" (Newman, Griffin \& Cole, 1989 as quoted in Nassaji\& Cumming, 2000, pp. 97-98).

\section{Dialogue Journal and Internalization}

Internalization is another important construct that Vygotsky used in order to explain how "the formation of the dialectical unity between social activity and higher mental functions" (Lantolf \& Poehner, 2014, p. 44). Vygotsky (1978) calls it "the international reconstruction of an external operation" (p. 56). According to him, this process consists of series of transformations such as the reconstruction of external activity so that it can occur internally and the transformation of the interpersonal process into intrapersonal. As a matter of fact, it takes place through the use of mediated activities, such as signs and tools. Signs are changes in the mind that are internally oriented whereas tools are changes in the environment and are externally oriented. There are two central processes - imitation and private speech that assist in internalization.

The term "imitation" has negative connotations as it was overused to mean a process of rotelearning in the classes where the principles of audiolingual pedagogy were thoroughly adopted. However,Vygotskyan theory of learning pays due regards to it, mainly because it is the process through which socio-culturally constructed forms of mediations are internalized (Vygotsky, 1978). As per socio-cultural theory, it has clearly specified both the ends and means. Newman and Holzman (1993) mention that it is "a critically important developmental activity because it is the chief means by which in early childhood human beings are related to as other than and in advance of who they are" (as cited in Lantolf \& Thorne, 2006, p. 167). It is because even if one the same thing is imitated, something new is created out of saying or doing the same thing. This has also been substantiated by neurological researches such as Icabonni et al. (1999). In this research, they found that mirror neurons for goal-directed and non-goal directed 
imitations are fired in various places of the brain (as cited in Lantolf \& Thorne, 2006, p. 168). This implies that the imitating process in Vygotksyan socio-cultural theory is by no means the same as the imitating process that is used in the behavioristic theory of learning.

When it comes to language acquisition- be it first or the second language, learners keep on imitating not only the exposure offered to them but also the language they eavesdrop as well. Here, the input they receive function as the models for the imitations. In fact, the limitations of these models are often considered as "essential building blocks for spontaneous speech" (Speidal 1989, as cited in Lantolf \& Thorne, 2006, p. 170). Thus, "novel forms children create are the consequence of imitation in the transformative understanding of the process as construed by Vygotsky, Baldwin, and Tomasello" (Lantolf \& Thorne, 2006, p. 172). Now, the question that arises here is whether or not imitation takes places in writing. There is no doubt that transformative imitation takes place while learners start to learn. For example, in kindergarten classes, teachers ask their students to copy certain letters or figures, often in the forms in which students should just move their pencils to make certain letter or figure. The same applies even when the learners are proficient enough to write, for instance, when we teach compositions, in a sense, we ask our students to imitate or follow certain models such as comparison and contrast, cause and effect, summary and response, etc. Dixon-Krauss (1995) in her action research found that the learners tend to imitate the responses or answers by the peers, who are comparatively more proficient than themselves. Nevertheless, they do not copy the same. Instead, they attempt to reconstruct to make the writings of their own.

Private speech is another central process of internalization which is mainly utilized by adults and is externalized inner speech that regulates mental and physical activities (Lantolf \& Thorne, 2006). Sometimes, private speech is confused with the inner speech, but they are not the same. Regarding their differences Fernyhough (2017) writes:

It [inner speech] has a cousin, "private speech," in which people talk to themselves audibly. If you say words to yourself, such as "Remember to get some coffee" or "stick to the plan," without making a sound, then you are using inner speech. If you say something similar to yourself out loud, it is private speech (p.76).

Alternatively, Vygotsky proposed that private speech is also a way that children "deliberately repurpose words that they have previously used successfully in social interactions with other individuals" (Fernyhough, 2017, p. 77). Many types of research carried out on private speech such as Gillette (1994), de Courcy (1993), Ellis (1999) shown that the use of private speech is useful for L2 development as well as cognitive development (as cited in Lantolf \& Thorne, 2006, p. 182-185).

Regarding the use of dialogue journal, the use of both private and inner speech can be very useful in a sense that learners who write these journals are involved in constant interaction 


\section{The Use of Dialogue Journals in an ESL Writing Class from Vygotskyan Perspective}

with their teachers or the peers who are more proficient than themselves through the written comments, feedbacks and probing questions. Furthermore, they might also be engaged in talking to themselves while they are thinking how they should write, what they should write or how to respond the comments or feedbacks given by their teachers. Therefore, while going through the several processes of dialogue journals, learners are provided with ample opportunities to have conversations between "I and You" and "I and me". In other words, the learners who write dialogue journals need to operate on the intra-mental plane and inter mental plane. Their operations on both the planes can be useful for enhancing writing skills and conceptual thinking.

\section{Writing as a Dialogue Between "You and I" and "I and Me"}

Though it looks, writing is neither a solitary task nor it is carried out in a vacuum. It needs to be situated. Therefore, while writers are engaged in writing, they are involved in several dialogues or conversations with other authors usually through their writings or with themselves, because they tend to make numerous decisions while they are writing, for example, why they want to write, whom they want to write, how they want to write? etc. Answering these questions makes them engaged in several conversations interpersonally, by talking with the people in real time and space; intra-personally, by self-taking. These features make writing interactive.

Vygotsky calls writing a written speech, which he considers the abstract representation of oral speech. In this sense, "Written speech is a speech monologue. It is a conversation with a white sheet of paper, with an imaginary or conceptualized interlocutor" (Rieber\& Carton, 1987, pp. 202-203). Thus, "writing is a special sort of dialogue" (Zebroski, 1994, p. 172). Vygotksy considers that it is difficult to master because a learner should be quite familiar with the symbolifcation process of what it expressed through oral speech. Additionally, he also calls it the algebra of oral speech because of its abstract nature. For this reason, he estimates that a child of eight years usually has the capacity of two-year child in terms of his or her written speech.

\section{Effects of Affects on Second Language Writing}

The above discussions clearly indicate that in order for learners to learn well, they should be able to expand their zone of proximal development. To reiterate what has already been mentioned, learners can better expand their zones of proximal developments if they are asked to solve the problems or carry out tasks that are beyond their existing capacities. With the assistance obtained from their teachers or the ones who are more proficient than themselves, however, they can solve those problems or carry out tasks. While discussing the types of the zone of proximal development, Mahn (2008) lists four major affecting factors that might determine whether the zone of proximal development of a learner expands or narrows. They include "1) 
physical and emotional- hunger, anxiety, fear, confidence, among many; 2) consequences of living in a loving home as opposed to not; 3 ) recent interactions with peers; 4) the way that interactions in socio-cultural environments are appropriated and internalized" (p. 117).

Second language acquisition is, by no means, uniquely different in terms of affecting factors. Yet there can be certain factors that might be unique in the case of second language acquisition, for instance, confidence in the production of language. Unlike the native speakers, non-native speakers can hardly ever be fully confident in the use of their second or foreign language, because they can only "master", not "appropriate" (Lantolf \&Thorne 2006, p. 161) their second language. Consequently, they cannot think through their second languages. For this reason, they might lose their self-confidence in using their second language. However, when they focus on their meanings or messages they like to communicate to their audience, they might build their confidence being involved themselves in the intra-mental plane. Highlighting this phenomenon, Mahn (2008) writes, "When students focus on meaning and are relieved of the pressure of producing error-free writing, they increasingly rely on inner speech and verbal thinking, both central concepts of conceptual thinking" (p.122). Additionally, second language writers have their own prior knowledge of writing, a way of making written expressions, identities, cultures, etc. All these factors might explicitly and implicitly influence the writers' affects, which, in turn, have effects upon the texts they produce. As per Krashen (1982), these are the factors that increase the affective filters that prevent learners from intaking comprehensible input given to them.

While learners are learning anything, they can have a sense of fear or anxiety. Generally, it is taken as a negative term, but it is not so in all cases and circumstances. There can be both facilitating and debilitating anxieties. The former, as its name suggests, constitute the type of anxiety that can be useful in solving problems or completing the tasks. For instance, if a student who has to complete an assignment might develop a kind of anxiety due to which he or she might be focused on carrying tasks planning in advance. Consequently, it is beneficial for him or her. However, sometimes, the anxiety can be debilitating in a sense that a learner might develop a feeling of "can't do" kind of attitude, which might ultimately cause him or her to lose self-confidence. Leont'ev (1981) also distinguishes similar kind of distinctions between stress and tension. For him, "the former is an impediment to learning while the latter acts as an impetus to learning" (as cited in Swain, Kinner \& Steinman, 2015, p. 82). The dialogic approach to teaching writing as followed while teaching dialogue journals can be very useful to avoid the debilitating anxieties and stresses as learners are encouraged to write for real communications; rather than completing certain kinds of assignments.

When the students write dialogue journals, they can overcome their fears and develop their writing fluency through meaningful communication in which the information they want to share becomes much more important than the language they use in their writing. Likewise, in 


\section{The Use of Dialogue Journals in an ESL Writing Class from Vygotskyan Perspective}

course of writing, they become aware of the forms, processes, meanings, etc., which are said to be higher order concerns; rather a grammatical accuracy. While they are writing, generally ESL students check their grammars, which break their flow of writing. This break can cause the disconnections between their inner speech and external speech, resulting in the loss of their ideas. "Dialogue journals help students overcome the disconnect between thinking and composing as they write more quickly" (Mahn, 2008, p. 131). Thus, by overcoming some effects that can negatively influence ESL writers' writing proficiency, they provide give them "the gift of confidence" (Mahn John-Steiner, 2002 a quoted in Mahn,2008, p. 136).

\section{Some Researches on Dialogue Journal Writing}

Several types of research have been carried out focusing on the various aspects of using dialogue journal. Such researches have been undertaken by collecting the data ranging from kindergarten to university students.

Tanner (1997) conducted a small survey research in which he collected the data form 12 teachers who were teaching to intermediate to advanced level ESL writers. It was found that $38.46 \%$ teachers had used dialogue journal as a means to enhance their students' writing skills. Among those who had used the dialogue journals, $60 \%$ maintained that they had asked their students to write the journals four times a week. The rest of the teacher had asked each student to write two or three journals a week. The teachers also reported the four benefits that their students had due to their use of dialogue journals. First, they were able to write more freely without being overly concerned about mistakes. Second, the journal allowed students to show express their personal feelings. Third, the use of journals made the students feel comfortable expressing their ideas. Fourth, students benefitted from writing journals. Regarding the types of feedback, they reported that they asked some probing questions, gave brief comments and shared their own experiences.

Ho (2003) studied how audio-taped dialogue journal in a university context of Taiwan can be effective. In doing so, he collected from 26 intermediate level students, who attended English III: Oral Communication class. The duration of the study was throughout a semester. The journal was a requirement, which was of $20 \%$ of the final grade. After the students submitted their audio journal. The teacher responded their journals as fully as possible. However, the focus here was to establish personal communication; rather than completing the assignments on the part of the students. Mostly, the teacher did not correct any mistakes except in the cases where errors caused problems in understanding the messages. He reported five major findings. First, the audio-tapped journals provided students the freedom to express what they dared not or did not get a chance to say in the class. Second, they also helped students perform well in class. Third, the journals were found to have been a means to enjoy one to one tutoring. Sometimes, students were found to be seeking individual help with a particular point in language. Fourth, 
these journals provided the students with opportunities to learn by doing. Finally, a teacher could better know about his students such as their learning goals, language proficiency levels, learning styles, motivation, interests and learning problems.

Collentine (2004) carried out research with a view to finding the answers to the three questions: 1) identification as a language learner and reflection on language learning experiences? 2) use of targeted language structure and functions? 3) consolidation of course content? In doing so, he collected the required data from eight learners selected by using purposive sampling form amongst the third-semester intermediate students enrolled for learning Spanish. The instructor asked the students to write journals using past tense verbs and subjunctive mood. They were given the tasks related to a narration, question formation and stating opinion using embedded clauses. As per the research question, the finding shows that the learners were able to identify themselves as learners. Another finding of this research was that both the highfrequency classroom participators and low proficiency classroom participators increased their use of the targeted forms and contents. Comparatively, those who were participated more in the classroom were found to have used the targeted forms and contents more than those of the ones who participated less in the classroom. He concludes his finding with the mention that the "learners utilized their journals as a forum in which to express accomplishments, challenges, and difficulties, enjoyment, goals, real-life experiences, and to ask questions about the Spanish language" (p. 332).

Talburt (1995) reports her finding of a qualitative case study research conducted in order to determine the extent to which dialogue journals can be effective means of exploring and creating possibilities for adult ESL learners. She collected the required data from a single case named Marina, who was a Russian refugee living in the US. As she was in the advanced grammar class offered to adult ESL learners, which was taught by the researcher herself. With her fine consent, the teacher asked Marina to keep journals for fifteen weeks. Usually, the student used to write a journal entry in a week and the teacher, after reading the journal by her student, would respond to it. Along with the journal, she also collected data from the audiotapped interview conducted at the end of the program. The collected data were analyzed based on the themes generated. The findings of her research include: 1) the student found writing dialogue journals as a means of expressing the self, experiences, identities, etc. But due to the lack of her English language proficiency, she thinks that all her desire to express have been circumscribed. 2) Along with the passage of the time, she seemed to have rebuilt her confidence and weakened sense of possibilities because of her increased proficiency in English. She concludes her research with the mention that dialogue journals can function as a space between the students and their teachers in which they can share their thoughts, reflections, understandings related to their society in general and their course contents in particular. 


\section{The Use of Dialogue Journals in an ESL Writing Class from Vygotskyan Perspective}

Lorrotta (2009) implemented dialogue journal in an adult literacy program while teaching ESL literacy students in writing for authentic communication. Throughout the semester, they would take two classes a week, each class of two hours. Out of the 17 students, she focused four students, who were the native speakers of Spanish. Her main goal of using dialogue journals was to establish communication in written English with each student. The researcher responded each journal entry of all the students in the same way as she would respond her friend's emails or letters. She would not correct errors the learners would do. Instead, she would push them for authentic, meaningful communication. She reports that her students found dialogue journals as a means to express what Gonzalez, Moll and Amanti (2005) calls "funds of knowledge" (as cited in Lorrotta, 2009, p. 40). Additionally, they get to know each other at the personal level as well. Overall, the ESL learners found that dialogue journal writing was an interesting activity as their written conversation progressed and the entries became more personal and authentic.

Miller (2007) studied ESL students' identities with the help of journals writing. For his study, he obtained the required data from 10 ESL students through observations, interviews in English and in their first languages, work samples, and the students' journals and diaries. The main finding of the research, like in many kinds of research in the use of dialogue journals, showed the potential values of using it because learners do not feel any kind of pressures or social pressures for the completion of the tasks. The most important find of this study is that dialogue journal writing is not only useful for enhancing the quality of writing of the second language learners, but also for helping them to identify their identities and voices while using English.

\section{Conclusion}

Many studies on the use of dialogue journals have been related to either adult literacy classes in which most of the participants are the immigrants or schools in the US context. However, there seems to have been done very little focusing on the multilingual writers in the US university contexts. Though they might resemble some characteristics of adult ESL learners, these populations are fundamentally different in terms of their prior knowledge, goals, and effects. Therefore, it seems that there is the dire need of carrying out researches by considering the multilingual writers in university context of the US. for three major reasons. First, unlike the principles of dialogue journals, the multilingual writers are often given written corrective feedback with the hope that they improve their essays as well as writing proficiency in English if they attempt to correct their writing products as per the feedbacks that are given by their instructors or professors. Second, as the instructors or professors require students to meet a certain standard of writing in their assignments, which might create debilitating anxiety amongst those writers who are not sufficiently proficient enough to write in standard English. Third, many teachers or professors assign writing journals, but they do so as an end, not a means to an end. Thus, restructuring of the assignment as per the Vygotskyan frameworks may not need substantial changes in the tasks. 


\section{References}

Auerbach, E. (1999). The power of writing, the writing of power: Approaches to Adult ESOL writing instruction. Focus on the Basics, 3 (D). Retrieved from: http://www.ncsall.net/ index.php@id=341.html

Cheyne, J. A., \& Tarulli, D. (1999). Dialogue, difference and voice in the zone of proximal development. Theory \& Psychology, Vol.9 (1), pp. 5-28.

Collentine, J. (2004). Dialogue journals as mediators of L2 learning: A sociocultural account. Hispania, Vol. 87 (2), pp.324-335.

Dixon Kraus, L. A. (1995). Partner reading and writing: Peer social dialogue and the zone of proximal development. Journal of Reading Behavior, Vol. 27 (1), pp. 45-63.

Fernyhough, C. (2017). Talking to ourselves. Scientific American, Vol. 317 (2), pp.74-79.

Garmon, A. M. (2001). The benefits of dialogue journals: What perspective teachers say. Teacher Education Quarterly, Fall, pp. 37-50.

Ho, Y. K. (2003). Audiotaped dialogue journals: An alternative form of speaking. ELT Journal, Vol. 57(3), pp. 269-277.

Holmes, V. L., \& Moulton, M. R. (1997). Dialogue journals as an ESL learning strategy. Journal of Adolescent and Adult Literacy, Vol. 40 (8), pp. 616-621.

Krashen, S. D. (1982). Principles and practice in second language acquisition. Oxford: Pergamon Press.

Lantolf, J. P.\& Thorne, S. L. (2006). Sociocultural theory and the genesis of second language development. Oxford: Oxford University Press

Linnel, K. M. (2010). Using dialogue journal to focus on form. Journal of Adult Education Information Series, Vol. 39(1), pp. 23-28.

Larrotta, C. (2009). Journaling in an adult ESL literacy program. New Directives for Adults and Continuing Education, pp. 35-44.

Long, M. (1996). The role of the linguistic environment in second language acquisition. In W. Ritchie \& T. Bhatia(Eds.), Handbook of second language acquisition, (pp.413-468). San Diego, CA: Academic Press.

Mahn, M. (2008). A dialogic approach to teaching L2 writing. Sociocultural Theory and the Teaching of Second Languages, pp. 115-138.

Miller, J. (2007). Inscribing identity: Insights from ESL students' journals. TESL Canada Journal Vol. 25(1), pp.23-40.

Peyton, J. K. (2000). Dialogue journals: Interactive writing to develop language and literacy. CAELA ESL Resources: Digests. Washington, DC: Center for Applied Linguistics. Retrieved from:http://www.cal.org/caela/esl_resources/digests/Dialogue_Journals.html

Rieber, R. W., \& Carton, A. S. (Eds.). (1978). The collected works of L. S. Vygotsky, Vol. 1. New York: Plenum Press.

Swain, M. Kinnear, P. \& Steinman, L. (2015). Sociocultural theory in second language 
education: An introduction through narratives ( $2^{\text {nd }}$ ed.). New York: Multilingual Matters. Talburt, S. (1995). Dialogue journals in adult ESL: Exploring and creating possibilities. College ESL, Vol.5 (2), pp. 67-82.

Tanner, M. (1997). The effects of dialogue journals in enhancing ESL student's writing. Dessert Language and Linguistic Society Symposium, Vol. 23(1), pp.113-120.

Vygotsky, L. S. (1978). Mind in society. The development of higher psychological processes. Cambridge, MA: Harvard University Press.

Zebrosky, J. T. (1994). Thinking through theory: Vygotskyan perspective on the teaching of writing. Portsmouth, NH: Boynton/Cook Publishers, Inc. 